\title{
Purpose of Nutrient Data Banks and Options for Eurofoods
}

\section{A.B. Cramwinckel}

Over the last 10 years or so, work has begun in several places in Europe to make food composition tables suitable for use with computers. In England in 1978, the first computerized version of the McCance and Widdowson table was made; in 1972, a working group was set up in The Netherlands to develop a computerized system for analyzing data from nutrient surveys, in the Federal Republic of Germany in 1978, the Lindas data bank started; and in 1980, the French Nutrition Foundation began development of a national data bank. Most European countries now have at least one nutrient data bank. The reason for the development of these data banks is obvious. As outlined by Bruce and Bergström [1], there has been an increasing demand for good and reliable food composition tables because of the increase in research on the relationship between diet and cancer. In these epidemio-logical studies, it has been found that not only the traditionally studied nutrients, but also a number of other components in the diet have to be considered. In addition, many studies now examine interactions between nutrients and the effect of dietary components on bioavailability and metabolism of nutrients.

Because of the complexity and cost of these data systems, it is necessary that there is cooperation not only within, but also between countries. As outlined in the Introduction, the Wageningen workshop was designed as a first step towards such cooperation in Europe. Increased compatibility of the nutrient data banks will increase and make easier the exchange of analytical data between the various countries of Europe.

Eurofoods is not the only organization working towards cooperation between countries on nutrient data banks. Within Europe, the Nordic countries, Denmark, Finland, Norway, and Sweden established Norfoods, a project group on food composition tables and nutrient data banks which was later joined by Iceland. Several months prior to the Wageningen Workshop, the first planning meeting of the International Network of Food Data Systems (Infoods) was held [2]. At this meeting, Young [3] referred to the importance of nutrient and food component data in understanding the role played by the nutritional environment in human health and welfare. On this basis alone, according to Young, it is obvious that these data are an essential resource for those concerned with food supply and its implications for the well-being of individuals and populations at large.

People have an interest in food composition tables and nutrient data banks for a variety of reasons. From a survey carried out prior to the Wageningen Workshop and reported in the paper by Arab, people were identified as carrying out three separate functions: using the data itself, food composition table and data base construction, and food analysis. Thus Eurofoods will make most progress if people with these three separate functions work together.

It is necessary to identify the requirements of the users, table/data base constructors, and 10

analysts. Users are a heterogeneous group of people. They comprise public authorities, epidemiologists, medical practitioners, food scientists, and those involved in home economics, the food industry, and information transfer. It is necessary to know what type of products and 
which nutrients and other constituents they would like included, what information they require about the data itself, and the type of software required to satisfy their needs. Constructors of food composition tables and nutrient data bases have their own wishes. They like to see a system which is complete, one which can be easily updated and which provides data on the updates made, and a system which gives information on the source and accuracy of the data. They also require a system which provides an adequate description of foods including mixed dishes and a good method for coding the foods. Analysts want agreement on suitable methods of analysis, on methods of sampling, on rounding figures, and on the description of mixed dishes.

In summary, Eurofoods is important because it will help to bring about cooperation between countries in Europe and between users, food composition table/nutrient data base constructors, and analysts. Cooperation is necessary, because among other reasons, there is not enough money to meet all the wishes of those involved with food composition tables and nutrient data bases.

References

Bruce, A.; Bergström, L.: User requirements for data bases and applications: nutrition research. Background paper prepared for the Planning Conference Concerning an International Network of Food Data Base Systems (Infoods), Bellagio, Italy 1983.

Rand, W.M.; Young, V.R.: Report of a Planning Conference Concerning an International Network of Food Data Base Systems (Infoods). Am J. clin. Nutr. 39: 144-151 (1984). Young, V.R.: Infoods: an introductory statement of purpose and goals of the Planning Conference. Background paper prepared for the Planning Conference Concerning an International Network of Food Data Base Systems (Infoods), Bellagio, Italy 1983. 